\title{
SPARK: Smart Power Assessment Rendering Kit
}

\author{
A. G. Paraspatki \\ Dept. of Information \\ Technology \\ NBN SInhgad School \\ of Engineering
}

\author{
R. M. Samant \\ Dept. of Information \\ Technology \\ NBN SInhgad School \\ of Engineering
}

\author{
P. A. Mehendale \\ Dept. of Information \\ Technology \\ NBN SInhgad School \\ of Engineering
}

\author{
S. S. Jahagirdar \\ Dept. of Information \\ Technology \\ NBN SInhgad School \\ of Engineering
}

\begin{abstract}
Use of smart home technology offers significant potential for everyday energy savings for each citizen. There are numerous schemes successfully implemented in western countries related to energy conservation. In Indian context, the issues encountered are that of diversity and consumer literacy about electricity consumption. In this paper, a novel approach is presented to address this issue on an interface designed to provide users with the real time energy consumption of appliance specific data. The proposed system uses wireless sensor networking for sensing and transmitting remotely monitored data gathered from an intelligent hardware system comprising of current sensors followed by a current calculating unit and a cloud server for communication and storage of data. XBee ${ }^{\circledR}$ transceivers, which are economical and reliable, are installed on electric appliances and a commonly available open source platform of Arduino microcontroller which calculates the current readings gathered by Hall Effect current sensor ACS712. The software system transfers the UID (Unique Identification) of each appliance to the cloud in order to uniquely identify each appliance. A user-friendly interface is developed to provide timely updates of the electricity consumption of the connected appliances. The system provides a real time analysis of the electricity consumed by individual appliances connected to the system.
\end{abstract}

\section{General Terms}

SPARK, Current sensing, Wireless transmission, Zigbee ${ }^{\circledR}$ protocol, Micro-controller, Cloud computing, Data analysis, Android interface, ACS712.

\section{Keywords}

Current sensor, Zigbee ${ }^{\circledR}$ protocol, Arduino UNO® microcontroller, Data processing, current sensing mechanism, data analysis, android application, $\mathrm{XBee}{ }^{\circledR}$

\section{INTRODUCTION}

Due to the rapid industrialization and transformation of the working mechanism energy has become a major component of our lives. Due to luxurious lifestyle and new facilities of electrical devices regarding remotely switching off the devices, the human tendency to cut off electricity of a device is largely ignored.

In a research carried out by daily mail, a renowned newspaper publishing site, reported that leaving the electronic gadgets in standby state accounts $10 \%$ of the average electricity bill [9]. Growth rate of electricity consumption in years 2013 to 2015 is $8.48 \%$. Various ways have been used to turn down the electricity consumption of a house. Installing compact fluorescent bulbs, automatic light sensors which help to conserve energy by sensing the presence and turning on/off the light accordingly. In order to install timed sensors where the requirement of light is not constant like in outdoor lighting. To install solar powered landscape lighting in order to save the cost of installing direct light bulbs at small intervals of distance and supplying sufficient light, making it look elegant yet operationally efficient. Adding solar power to it will be another method of energy conservation as in day time when the light is not required, the solar lighting will soak up the sun's energy and work efficiently till dawn as and when required.

Modernization has brought about a change in the way tools are being used. The electric appliances and machines play a vital role in this change. Some processes are carried out manually by noting the readings of each household in order to provide the customer with the electric consumption of the whole house as a unit. This standard method provides us with the overall consumption of a household which makes it difficult to control the electric consumption as the area which is consuming excess of electricity is unknown in order to reduce its use. Thus to enable the tracking of the energy consumption of individual appliances, an energy tracking system based on electricity tracking and analysis is being introduced in this paper.

SPARK comprises of three main components: a wireless sensing mechanism, data processing and storage and an energy monitoring and data analyzing module. The sensors will read the current flow through the electrical appliance and transmit this data to the micro-controller using $\mathrm{XBee}{ }^{\circledR}$ transceiver. This transmitted data is then used to calculate the cost against the energy consumed. This calculated information along with the data is sent to a public cloud named Thinger.io. The cloud provides an access to the data analysis module on an individual interfaces. A mobile application is used to display the monitoring of the energy consumption and the on/off state of the electrical appliance connected. The system enables users to save energy by monitoring home appliances through mobile device. SPARK can be used for energy consumption monitoring, and long-term energy conservation planning.

\section{RELATED WORK}

There are numerous methodologies proposed for monitoring the energy consumption of electrical appliances. Various techniques are developed for transmission of this data over the network. Some of these techniques include wireless sensing mechanism, data processing and storage module and data analyzing module.

Smart home environment makes use of wireless sensing network platforms to integrate individual devices. These devices cooperate with other devices independently to provide intelligent services for users. In this system, sensors measure the actual power consumption and ON/OFF status and sends it to the information processing unit via Zigbee ${ }^{\circledR}$ communication protocol. A wireless sensor has three technical components: a MCU (micro-controller unit) with an ADC, a sensing unit, and an $X B e e{ }^{\circledR}[14]$ transceiver which is known for efficient and cost effective transmission protocol. Use of 
the PostgreSQL database and a unique sensing ID for each individual appliance brings ease in operation [1].

Smart home automation technique enables us to control the whole technological environment around us through centralized control system. It increases the ease in operation and management thus increasing the quality of life, especially that of the disabled and elderly [2] [3]. Just by having basic computer knowledge, a person can handle all the appliances connected and can monitor their consumption.

Remote current measurement enables the user to sense the electric current consumption by using current sensor [4], photo-voltaic cell, micro-controller and Zigbee ${ }^{\circledR}$ protocol. LabVIEW program is used to establish connection for $\mathrm{I} / \mathrm{O}$ instruments. It is a high level API which retrieves the data from PV through XBee ${ }^{\circledR}$.

A prepaid metering scheme is used to control the usage of electricity. The effective awareness of the consumption is best produced through this system. The electricity consumption recorded by all meters under a distribution transformer is collected at a point through Power Line Carrier (PLC) and are sent over to the server through GSM network [5].

Smart metering network uses a smart metering device which captures current and voltage waveform and performs compression function and feature extraction. Used for monitoring building integrated electronic vehicle charging network [6].

Smart power metering system uses analog measurement circuit consisting of a relay and a current sensing circuit (ACS712) [12], controller (Arduino UNO [15] based on 80megha328), IOT consisting Raspberry pi- Ethernet interface, cloud storage, web hosting, UI (graphical representation of energy usage) [6].

Single plug-in sensor which is used to plug in the main socket and the test outlet is plugged into the plug-in sensor. Oscilloscope was attached to it which is then connected to the laptop which analyses the noise produced. This system uses oscilloscope to detect changes in signals and detecting noise using machine learning algorithm [7] [8].

\section{METHODOLOGY}

The figure 1 shows the block diagram of SPARK, which is divided into three sections: 3.1) Wireless Sensing Mechanism using WSN 3.2) Data processing and storage and 3.3) Energy monitoring and data analyzing module.

\subsection{Wireless sensing mechanism}

Introducing a current measuring module that measures the amount of electric current consumed by electric appliances.
This is achieved by Hall Effect current sensor ACS712. This sensor works on the principle where a conductor is placed in a magnetic field, voltage is created across its edges perpendicular to the direction of both current and magnetic field. The voltage generated is called as Hall voltage which is in micro-volts.

Zigbee® is a wireless technology developed as an open global standard to address the need of low cost, low power wireless M2M (machine to machine) network. Zigbee ${ }^{\circledR}$ operates on the IEEE 802.15.4 physical radio specification.

The sensor transmits the analog data using Zigbee ${ }^{\circledR}$ protocol by an $\mathrm{XBee}{ }^{\circledR}$ transmitter. This analog data will then be converted in digital format using ADC. The XBee ${ }^{\circledR}$ receiver which is situated at the calculation module receives the digital signals as the input. This transmission is based on a principal of wireless sensing networks in which digital data is transferred between two nodes of any system through Zigbee ${ }^{\circledR}$ protocol.

The calculation module consists of an Arduino UNO microcontroller and an $\mathrm{XBee}{ }^{\circledR}$ receiver which receives the data from the current sensing module.

Arduino UNO micro-controller board is based on the ATmega328P which operates at $5 \mathrm{~V}$ as well as $3.3 \mathrm{~V}$. The Arduino Uno has a provision of using an USB and an IDE to write and load code onto the board.

The amount of electricity consumed by the electric appliance is transmitted as a digital input to the calculation module. The cost against the amount of electricity consumed is calculated, as per the standard electricity consumption rates, for individual appliance. The calculated cost is transmitted to the data processing and storage module using through Wi-Fi using Ethernet shield. The transmission consists of a Unique identification number (UID) generated by the MAC address of the transmitting ZigBee ${ }^{\circledR}$ respectively.

\subsection{Data processing and storage}

The cloud server containing the data received through an Ethernet shield stores the data into its database. A unique identification number (UID) is transmitted by the Ethernet shield which contains the cost effective consumption of the respective electrical appliance. The UID maintains the individuality of the appliance. The analysis of the electricity consumed is generated as an output based upon the time analysis of the electricity consumption of the appliance and hence produces a graphical representation in the form of frequency distribution graph. The authenticated users can view their profile containing the analysis of their respective electric appliances.

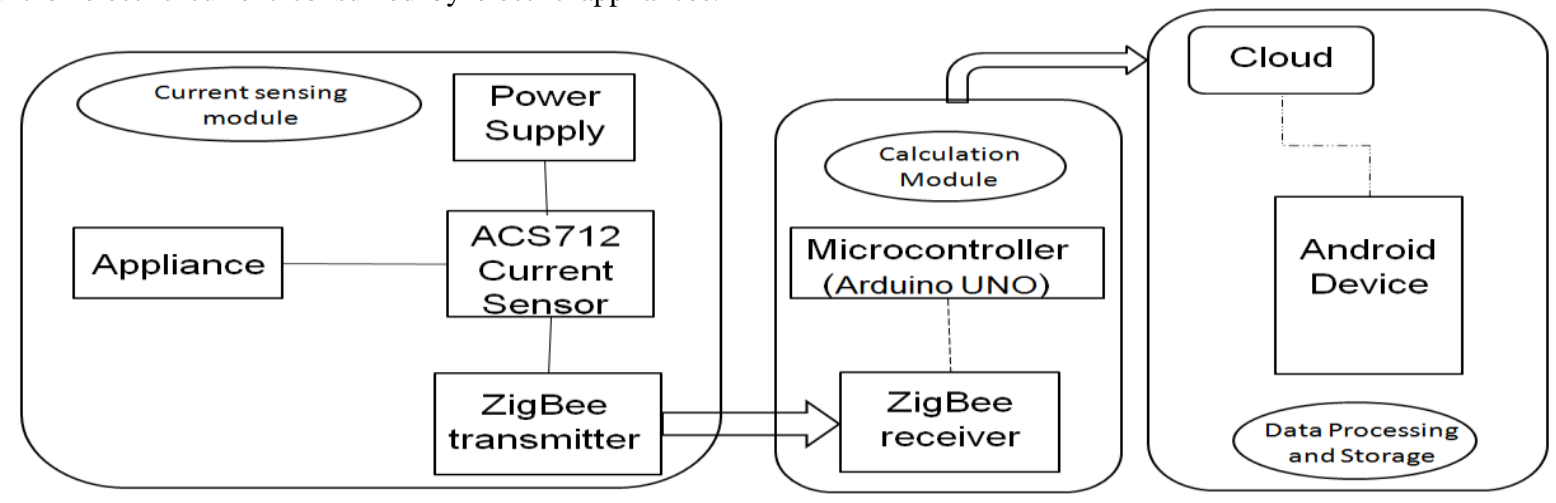

Fig1. Block Diagram of SPARK 


\subsection{Energy monitoring and data analyzing module}

In this module, an interactive Android application, called SPARK, is proposed, wherein individual users can register their account. This account will be created on Thinger.io cloud which will then provide the analyzed data of the respective electrical appliance registered on the users account. The individual user can authenticate by providing the necessary details by which the user can view analysis reports in their account created on SPARK.

\section{OBSERVATIONS AND RESULTS}

Table 1. Power consumption measurement using $40 \mathrm{~W}$ Tungsten Filament bulb

\begin{tabular}{|c|c|c|c|c|c|c|}
\hline \multicolumn{7}{|c|}{ Bulb Rating $40 \mathrm{~W}$} \\
\hline $\begin{array}{c}\text { Bulb } \\
\text { Status }\end{array}$ & OFF & ON & OFF & OFF & ON & OFF \\
\hline Time & $1 \mathrm{pm}$ & $\begin{array}{c}1.30 \\
\mathrm{pm}\end{array}$ & $2 \mathrm{pm}$ & $\begin{array}{c}2.30 \\
\mathrm{pm}\end{array}$ & $3 \mathrm{pm}$ & $\begin{array}{c}3.30 \\
\mathrm{pm}\end{array}$ \\
$\begin{array}{c}\text { Duration } \\
(30 \text { min) }\end{array}$ & $\begin{array}{c}\text { (Initial } \\
\text { reading) }\end{array}$ & & & & & \\
\hline
\end{tabular}

\begin{tabular}{|c|l|l|l|l|l|l|}
\hline $\begin{array}{c}\text { Readings } \\
\text { (Amp) }\end{array}$ & 0.028 & 0.030 & 0.131 & 0.034 & 0.028 & 0.150 \\
\hline
\end{tabular}

Table 2. Power consumption measurement using $100 \mathrm{~W}$ Tungsten Filament bulb

\begin{tabular}{|c|c|c|c|c|c|c|}
\hline \multicolumn{7}{|c|}{ Bulb Rating 100W } \\
\hline $\begin{array}{c}\text { Bulb } \\
\text { Status }\end{array}$ & OFF & ON & OFF & OFF & ON & OFF \\
\hline $\begin{array}{c}\text { Time } \\
\text { Duration } \\
\text { (30 min) }\end{array}$ & $\begin{array}{c}1 \text { pm } \\
\text { (Initial } \\
\text { reading) }\end{array}$ & $\begin{array}{c}1.30 \\
\mathrm{pm}\end{array}$ & $2 \mathrm{pm}$ & $\begin{array}{c}2.30 \\
\mathrm{pm}\end{array}$ & $3 \mathrm{pm}$ & $\begin{array}{c}3.30 \\
\mathrm{pm}\end{array}$ \\
\hline $\begin{array}{c}\text { Readings } \\
\text { (Amp) }\end{array}$ & 0.028 & 0.030 & 0.392 & 0.038 & 0.028 & 0.421 \\
\hline
\end{tabular}

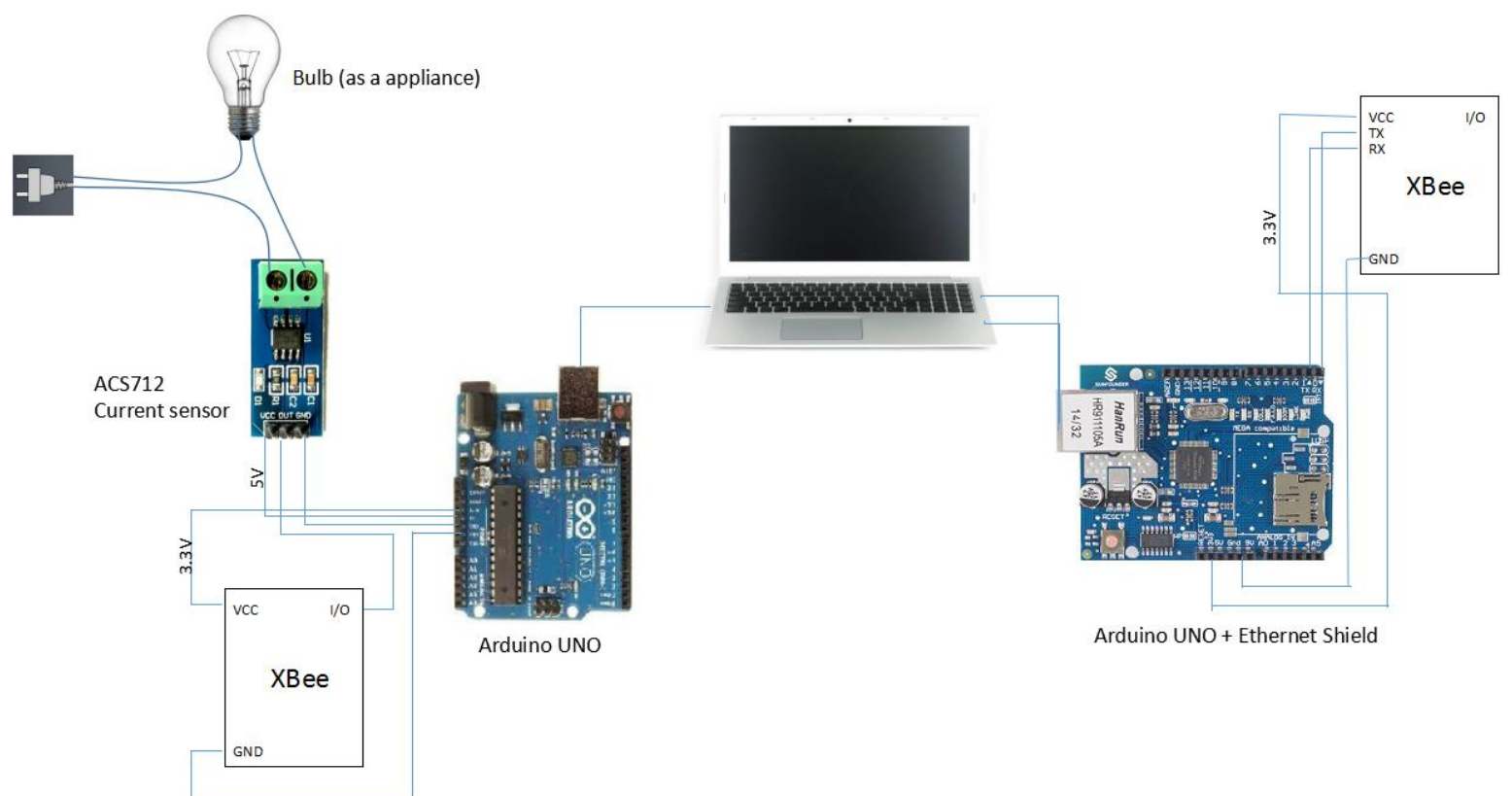

Fig 2. Circuit Diagram of SPARK

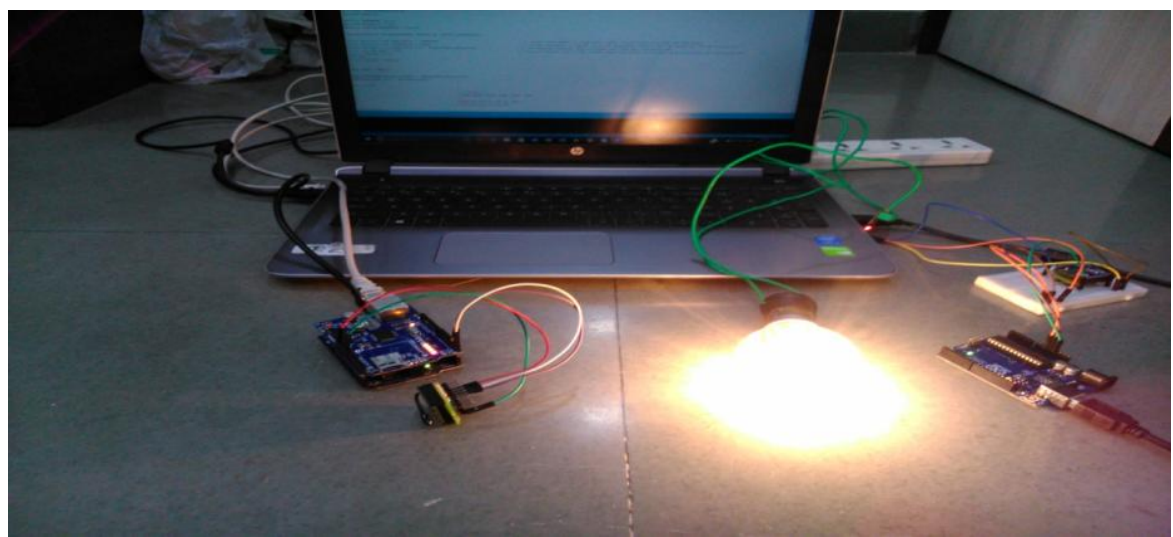

Fig 3. Hardware implementation of SPARK 


\section{CONCLUSION}

This paper presents, SPARK: a novel and integrated system of measurement of electric current which provides a power consumption analysis of an individual appliances connected in the system. It helps the user to monitor, analysis and makes them aware of real time power consumption of connected appliances on an interactive, user friendly interface thus enabling the user to save electricity.

\section{REFERENCES}

[1] H. R. Chi, K. F. Tsang, C. K. Wu, and Faan Hei Hung, "ZigBee based wireless sensor network in smart metering," in IECON 2016 - 42nd Annual Conference of the IEEE Industrial Electronics Society, 2016, pp. 56635666 .

[2] S. N. Patel, T. Robertson, J. A. Kientz, M. S. Reynolds, and G. D. Abowd, "At the Flick of a Switch: Detecting and Classifying Unique Electrical Events on the Residential Power Line (Nominated for the Best Paper Award)," in UbiComp 2007: Ubiquitous Computing, Berlin, Heidelberg: Springer Berlin Heidelberg, 2007, pp. 271288.

[3] A. Kurde and V. . Kulkarni, "IOT Based Smart Power Metering,” Int. J. Sci. Res. Publ., vol. 6, no. 9, pp. 411$415,2016$.

[4] N. C. F. Tse, W. H. Lau, and J. Y. C. Chan, "ZigBee based smart metering network for monitoring building integrated electric vehicle charging circuits," in IEEE PES General Meeting, 2010, pp. 1-5.

[5] M. S. Parvin and S. M. L. Kabir, "A framework of a smart system for prepaid electric metering scheme," in 2015 4th International Conference on Informatics, Electronics and Vision, ICIEV 2015, 2015, pp. 1-5.

[6] S. Zahurul, N. Mariun, V. Grozescu, M. Lutfi, H. Hashim, M. Amrana, and I. Izham, "Development of a prototype for remote current measurements of PV panel using WSN," Int. J. Smart Grid Clean Energy, vol. 3, no. 2, pp. 241-246, 2014.

[7] M. Sági, D. Mijić, D. Milinkov, and B. Bogovac, "Smart home automation," 20th Telecommun. Forum TELFOR 2012, vol. 7, pp. 1512-1515, Nov. 2012.

[8] W. H. Kim, S. Lee, and J. Hwang, "Real-time energy monitoring and controlling system based on ZigBee sensor networks," in Procedia Computer Science, 2011, vol. 5, pp. 794-797.

[9] Use people power to cut your energy bills, consumers urged: Record levels of discontent with Big Six providers is revealed www.dailymail.co.uk/news/article$2578771 /$ Ues-people-power-cut-energy-bills-consumers-
urged-Record-levels-discontent-Big-Six-providersrevealed.html

[10] SeungJoon Lee, Min Chul Kim, Yeo Sun Kyung, Kyung Kwon Jung, JooWoong Kim, Yong Gu Lee and Ki Hwan Eom, "A Design of U-system for Group Management Using Wireless Sensor Network and Android Device", International Journal of Advanced Science and Technology Vol. 35, October, 2011 International Journal of Advanced Science and Technology Vol. 35, October, 2011

[11] Li Ma, Lei Gu and Jin Wang, "Research and development of mobile application on Android Platform", International Journal of Advanced Science and Technology Vol. 35, October, 2011

[12] Santosh Kumar and R. H. Goudar, "Cloud Computing Research Issues, Challenges, Architecture, Platforms and Applications: A Survey", International Journal of Future Computer and Communication, Vol. 1, No. 4, December 2012

[13] Takeshi Saitoh, Tomoyuki Osaki, Ryosuke Konishi, Kazunori Sugahara, "Current Sensor Based Home Appliance and State of Appliance Recognition", SICE Journal of Control, Measurement, and System Integration, Vol. 3, No. 2, pp. 086-093, March 2010

[14] Muthu Ramya.C, Shanmugaraj.M, Prabakaran.R, "STUDY ON ZIGBEE TECHNOLOGY", DOI 10.1109/ICECTECH.2011.5942102

[15] André Araújo, David Portugal, Micael S. Couceiro and Rui P. Rocha,"Integrating Arduino-based Educational Mobile Robots in ROS",Proceedings of the 13th International Conference on Mobile Robots and Competitions April 24, 2013. Lisbon, Portugal

[16] Saurabh Bhardwaj, Priyanka Chouhan, Richa Sharma, Preeti Sharma, "Android Operating Systems", International Journal of Engineering Technology and management research, Volume 1, Issue 1, February 2013

[17] Arya Krishna S., Lizy Abraha, "Analysis of Different Hall Effect Current Sensors for Space Applications", IJISET International Journal of Innovative Science, Engineering \& Technology, Vol. 1 Issue 5, July 2014.

[18] M V Uttam Tej, M.Rajasekhara Babu,Dhanaraj Cheelu, P Venkata Krishna, "Remote Access of Building Management System Alarms Using Android Mobile Devices ",International Journal of Computer Information Systems, Vol. 2, No. 2, 2011

[19] Venkatesh Neelapala, Dr. S. Malarvizhi, "Environment Monitoring System Based On Wireless Sensor Networks Using Open Source Hardware", IJERSS, Volume 2, issue 4, April 2015. 